\title{
DESIGN OF A NEW GENERATION "SOLAR ANTBOT” FOR MANKIND
}

\author{
Bidrohi Bhattacharjee $^{1^{*}}$, Pradip Kumar Sadhu ${ }^{1}$, Ankur Ganguly ${ }^{2}$ \\ and Ashok Kumar Naskar ${ }^{2}$ \\ ${ }^{1}$ Department of Electrical Engineering, Indian Institute of Technology (Indian \\ School of Mines), Dhanbad, Jharkhand-826004, India \\ ${ }^{2}$ Department of Electrical Engineering, Techno International Batanagar, Kolkata- \\ 700141, India \\ *onlybidrohi@gmail.com
}

\begin{abstract}
The world is constantly going on the path of automated technology day by day and robotics is having a vital role in it (plays a vital role in this section as well). Hence, this robot called, "Solar AntBot" is made to automatically pick and place different objects with different colours by scanning ArUco markers by using its mechanical arm. Two microcontrollers are used in this case, Arduino and Raspberry $\mathrm{Pi}$ and serial communication is done between them to perform its job. It is designed in such a way that it is charged automatically when the charge percentage drops below a certain level. Power bank has been used as a backup device. In this particular model the Bot is charged using solar charger to make it eco-friendly, apart from that it can also be charged by any means of electrical power of same voltage and ampere rating. The main application area is autonomous based vehicles and restaurant food delivery system.
\end{abstract}

Keywords-Solar AntBot, Raspberry Pi, Power bank, Battery, Ant Hill

\section{INTRODUCTION}

The Solar AntBot [1]-[4] technology states the need of automation and robotics as well as renewable energy [5]-[7] source in modern days and to give an example of automation with renewable energy source [8]-[10], this robot, called "Solar AntBot" [11]-[15] is constructed keeping in mind to reduce human labor, time taken to complete a task and use the renewable energy [16]-[17] for its operation. It moves in its way following a black line which leads it to the source of blocks and as well as to the destination to place the blocks. The black line is also stretched to the place to keep the garbage blocks from the destination part. It is powered by solar panel which is controlled by a charge controller. This robot [18]-[20] can be used as a waiter in restaurants or as a substitute of man labor in material loading and unloading in go down or stores etc. With the use of this automated method with minimum running cost [21], it is possible to deliver food from restaurant in less time. Besides this, car control would be much easier. This AntBot technology is much better than the AntBot of the past. The homing and outdoor recital of the solar AntBot when its pathway incorporation mode was set to the auto mode, which means that it computed both the distance travelled and its orientation on the basis of stride integration alone. The whole system is portable as AntBot has its own power supply and it is possible to extend the working time of AndBot by selecting the amperehour capacity of the battery. Moreover it does not have any effect during power supply

Received: September 15, 2019

Reviewed: November 21, 2019

Accepted: December 2, 2019

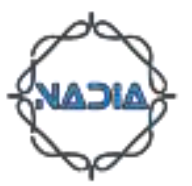


failure or shut down. This technology very useful in those places where there is no global positioning system (GPS) available, such as transporting goods to remote locations, automatic crop growers and maintenance, autonomous marine navigations.

\section{SOLAR ANTBOT TECHNOLOGY}

In case of the first generation robots, the main sensor was made up of three pairs of polarization-sensitive units (POL-units) with a spectral sensitivity in the visible range. The pole units were arranged in different orientation like $0^{0,} 60^{\circ}$ and $120^{\circ}$ [22] accordingly. The polarization sensor was composed of three pairs of photo diodes joined with linear polarizes [23] and concomitantly with a bio-inspired. Bio-inspired approaches have also been adopted with cameras in the visible range [23]. The major drawback of those technologies is that, negation capacity is very poor with high initial cost.

The main inspiration for the solar AntBot has been found from desert ants. They go out for food in the desert and return to their destination in the perfect way. Following the desert ants, the solar AntBot has been created in the same way with appropriate navigation, so that they can move without GPS. Solar AntBot technology is a fully automated system that allows complex tasks to be completed in a relatively short time, in a coherent way. By reducing its running cost using green energy, it brought into the hands of common people. The walking robots move without global positioning system (GPS) by the help of appropriate programmable circuit with wireless communication. Solar AntBot navigation systems differ from those of other AntBot. The robot is made fully of Aluminum and it has mainly three parts - base, arm and catcher, roof or carrier. At the lower surface of the Bot, the line following the sensor is fitted at the opposite surface. The Arduino Nano, Raspberry Pi, L98N motor diver are connected through a single piece of Vero board. At the lower surface, the D.C battery is also connected and at the opposite surface, the power bank is kept and connected with Raspberry Pi. The arm is moved by the Standard servo and the catcher is moved by micro servo. The movement of the arm is along ' $\mathrm{Y}$ ' axis and catcher along ' $\mathrm{X}$ ' axis. The arm is moved over 120 degree with the help of one mechanical support and one rubber band. The arm is required to move 120 degree only when the robot carries two blocks at a time; otherwise, the arm is only moved 90 degree. The Vero board consisting of Raspberry Pi, Arduino Nano, L298N motor driver is mounted at a certain small distance from the body surface so that the heat released by each component is easily dissipated into the air. The roof is supported by four metal supports which are tall enough to lift the roof over the whole circuit mentioned previously. Over the roof, an extra place is there to carry the second block picked up by the robot and that is tilted at an angle of 15 degree so that the block is helped to be picked up by the catcher at the time of placing the block to its final position. The design of power circuit based on solar energy. The arms of AntBot move vertically ups and downs up to $120^{\circ}$ and used to lift and drop the object or load when required. The catcher is located at the very front of the arms. The two separate parts of the catchers acts horizontally to catch or release the load. The wheel section used to give mobility to the AntBot. Power circuit built with solar panel, solar charge controller and power bank with proper rating. The tenor of AntBot is determined by the rating of the power bank. Robotics function is controlled by the Stride integration methods. The robot goes step by step towards destination and the overall distance to the walkway depends on the number of steps. Total moving distance $\mathrm{D}_{\mathrm{i}}$ is calculated depending on the number of steps walked.

Therefore, The moving distance $-D_{i}=S_{T} \times d_{s}$

Where, $d_{S}=$ Average distance covered per stride, depending on the step parameters $S_{t}=$ Number of strides performed.

The entire journey is guided by the relentless function of its components. 


\section{LIST OF MATERIALS}

Table I. Component specification

\begin{tabular}{|c|c|}
\hline Name of the component & Specification \\
\hline Microcontrollers & $\begin{array}{l}\text { 1. Raspberry Pi 3B . 230mA (1.13W) } \\
\text { 400\% CPU load - 730mA (3.7W) } \\
\text { 2. Arduino Nano 7W, (5V-7V) }\end{array}$ \\
\hline Actuators & $\begin{array}{l}\text { 1. Micro Servo }(0.55 \mathrm{~A}, 2.75 \mathrm{~A}) \\
\text { 2. Standard Servo }(0.8 \mathrm{~A}, 5 \mathrm{~V}, 4 \mathrm{~W}) \\
\text { 3. Two number of Johnson motors }(4.3 \mathrm{~A}, 12 \mathrm{~V}, 51.6 \mathrm{~W})\end{array}$ \\
\hline Driver & L298N Motor driver $(5 \mathrm{~V}, 0.2 \mathrm{~W})$ \\
\hline Else & $\begin{array}{l}\text { 1. Digital Buzzer }(0.15 \mathrm{~A}, 5 \mathrm{~V}) \\
\text { 2. RGB LED } \\
\text { 3. Line following sensor }(0.75 \mathrm{~A}, 2.47 \mathrm{~W}) \\
\text { 4. } 1 \mathrm{~K} \text { Potentiometer } \\
\text { 5. Vero board } \\
\text { 6. Solar Charge controller }(15 \mathrm{~W}, 12 \mathrm{~V}) \\
\text { 7. Pi cam } \\
\text { 8. Solar panel of } 15 \mathrm{~W}, 12 \mathrm{~V} \\
\text { 9. Power bank } 12 \mathrm{~V}, 25000 \mathrm{mAh} \text {. }\end{array}$ \\
\hline Connecting wire & $2 \mathrm{~m}$ single core \\
\hline
\end{tabular}

\section{ELECTRICAL CONNECTIONS}

Electrical connections - All the electrical connections are made on Vero board, apart from that they can also be done through PCB's.

Table II. Connections Between L298N And Raspberry 3B

\begin{tabular}{|c|c|}
\hline L298N Motor Driver & RPI 3B \\
\hline EN-A & PIN 37 \\
\hline IN1 & PIN33 \\
\hline IN2 & PIN35 \\
\hline IN3 & PIN36 \\
\hline IN4 & PIN38 \\
\hline EN-B & PIN40 \\
\hline$+5 V$ & PIN2 \\
\hline GND & PIN39 \\
\hline EN-A & PIN 37 \\
\hline
\end{tabular}

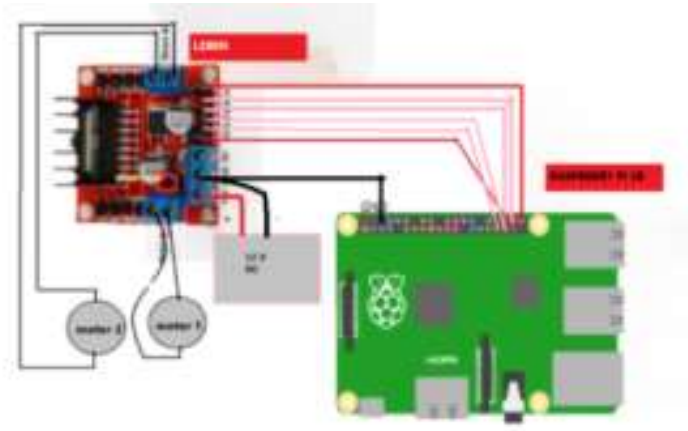

Fig. 1 Connections between L298N and RPI 3B 
Table III. Connection between L298N and dc motors

\begin{tabular}{|c|c|}
\hline $\begin{array}{l}\text { MOTOR 1 AND } \\
\text { MOTOR 2 }\end{array}$ & L298N \\
\hline M1 & OUT1 \\
\hline M2 & OUT2 \\
\hline M1 & OUT3 \\
\hline M2 & OUT4 \\
\hline
\end{tabular}

Table IV. Connection between rpi3b, li-ion battery and L298N

\begin{tabular}{|c|c|}
\hline L298N & Connected To \\
\hline $12 \mathrm{~V}$ & $12 \mathrm{~V}($ LI-ION) \\
\hline GND & GND(LI-ION AND RPI3B) \\
\hline $5 \mathrm{~V}$ & RPI3B PIN 3 \\
\hline
\end{tabular}

Table V. Connections between Arduino Nano and standard servo motors.

\begin{tabular}{|c|c|}
\hline Arduino Nano Pin & Standard Servo Pin \\
\hline D3 & DATA PIN(WHITE) \\
\hline GND & GND PIN(BLACK) \\
\hline 5V & VCC PIN(RED) \\
\hline
\end{tabular}

Table VI. Connections between Arduino Nano and micro servo

\begin{tabular}{|c|c|}
\hline Arduino Nano Pin & Micro Servo Pin \\
\hline D6 & DATA PIN(ORANGE) \\
\hline GND & GND PIN(BROWN) \\
\hline 5V & VCC PIN(RED) \\
\hline
\end{tabular}

Table VII. Connections between Arduino Nano and line following sensor

\begin{tabular}{|c|c|}
\hline $\begin{array}{c}\text { Line Following } \\
\text { Sensor Pin }\end{array}$ & Arduino Nano/ Potentiometer Pin \\
\hline 1 & ARDUINO(A0) \\
\hline 2 & POTENTIOMETER (VARIABLE END) \\
\hline 4 & POTENTIOMETER (VARIABLE END) \\
\hline 5 & ARDUINO(A4) \\
\hline 6 & POTENTIOMETER (VARIABLE END) \\
\hline 15 & ARDUINO GND \\
\hline 16 & ARDUINO GND \\
\hline 17 & ARDUINO GND \\
\hline 18 & ARDUINO GND \\
\hline 19 & ARDUINO 3V3 \\
\hline 20 & ARDUINO 3V3 \\
\hline
\end{tabular}

Table VIII. Connections between Arduino Nano And Buzzer

\begin{tabular}{|c|c|}
\hline Arduino Nano Pin & Buzzer Pin \\
\hline $5 \mathrm{~V}$ & VCC \\
\hline D13 & I/O \\
\hline GND & GND \\
\hline
\end{tabular}

Table IX. Raspberry Pi3b to RGB LED Connections

\begin{tabular}{|c|c|}
\hline RASPBERRY PI3B & RGB LED $($ Cmmn. Cathode $)$ \\
\hline PIN NO. 11 & $1^{\text {st }}$ PIN \\
\hline GND & GND PIN OF LED $\left(2^{\text {nd }}\right)$ \\
\hline PIN NO. 13 & $3^{\text {rd }}$ PIN \\
\hline
\end{tabular}


Connections between RPI 3B, L298N, Motor (1\&2) and DC battery.

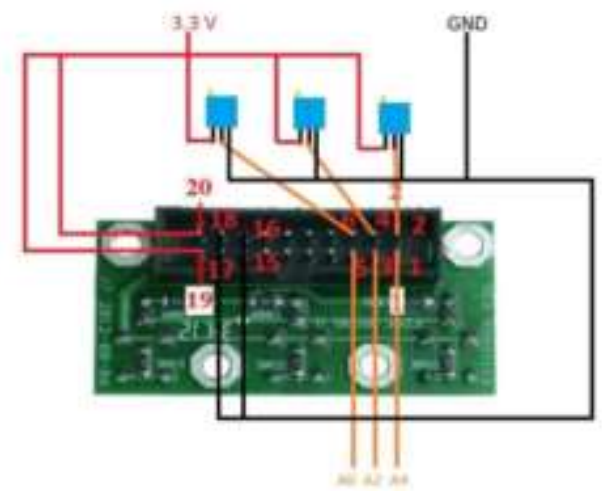

Fig. 2 Connections between Arduino Nano and L298N
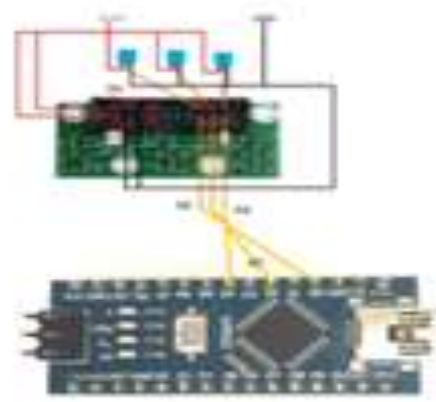

Fig. 3 Connections between Raspberry PI3B, Arduino Nano and Power bank

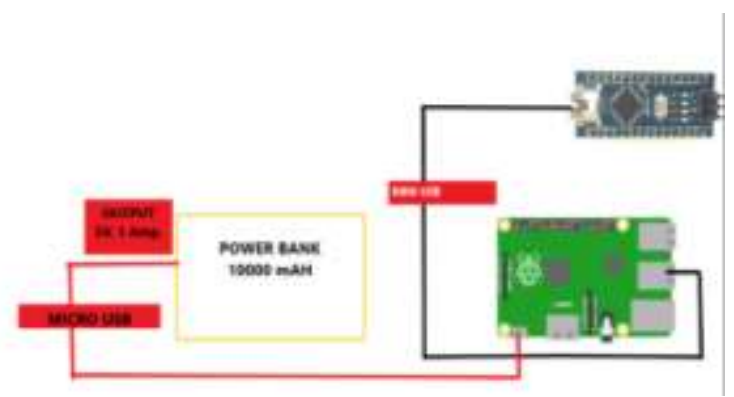

Fig. 4 Connections between Arduino Nano, L298N, Whiteline sensor, Standard Servo and Micro Servo

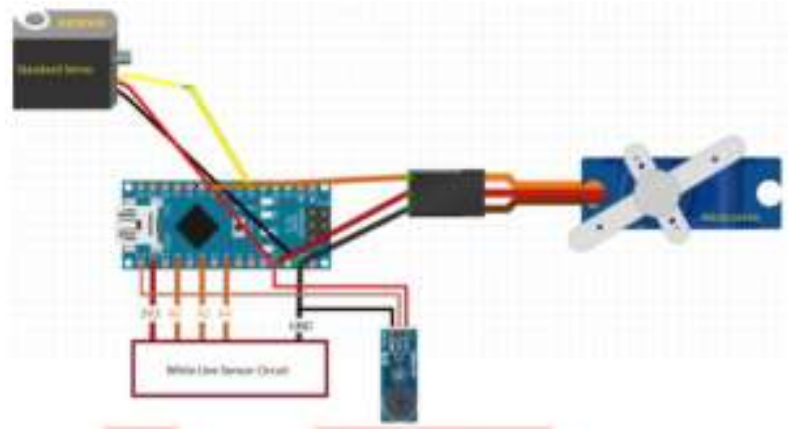

Fig. 5 Internal connections between Standard Servo and Sensor Circuit 


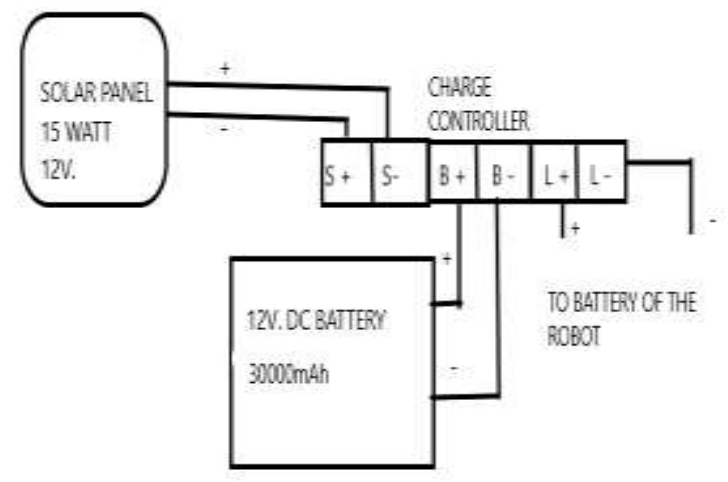

Fig. 6 Connection diagram of Solar panel with charge controller, battery and load

The $15 \mathrm{~W}, 12 \mathrm{~V}$ solar panel is connected to the AntBot's power circuit through a charge controller. The cells of the solar panel produce electricity directly from sun light. The generated DC voltage available at the terminal points of the panel. But the generated DC voltage is unregulated, because the amount of voltage depends on the intensity of the sun light and the intensity of sunlight changes throughout the solar hours. One of the main functions of the charge controller is to convert the unregulated DC voltage to the regulated DC voltage and another task is to charge the battery. Charge controller consists of six numbers of terminals. $15 \mathrm{~W}$ Solar panel connected in between the $\mathrm{S}^{+}$and $\mathrm{S}^{-}$.

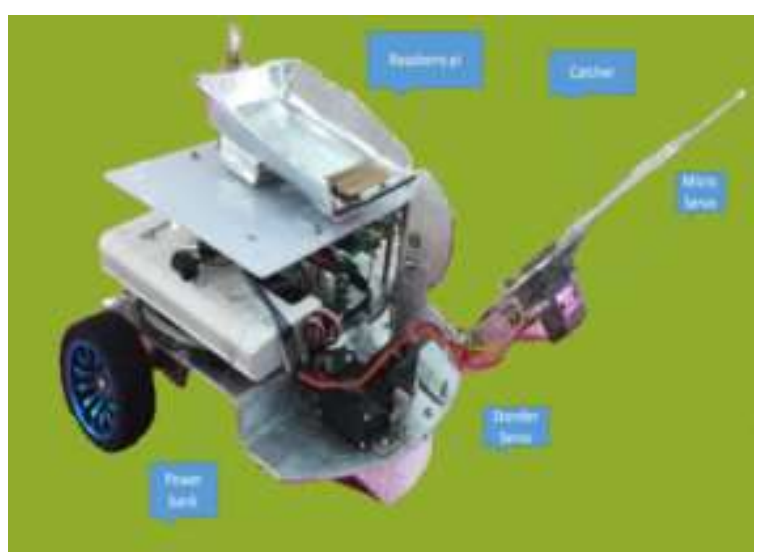

Fig. 7 Different component of Solar AntBot

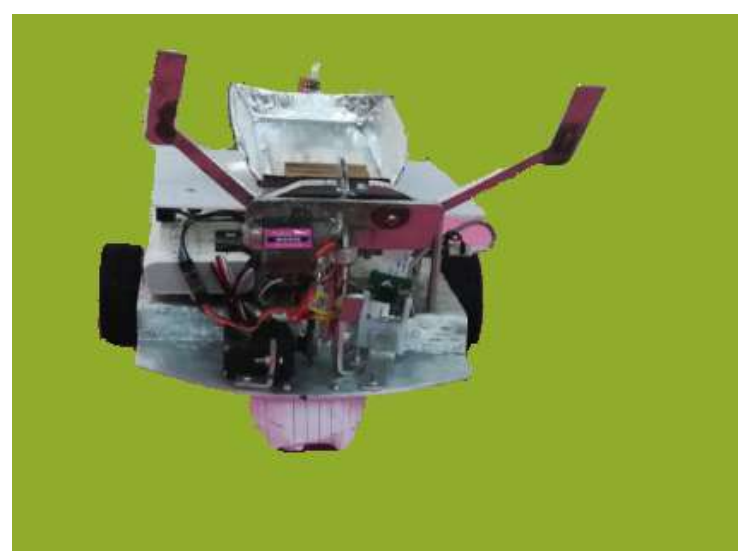

Fig. 8 Front view of Solar AntBot 


\section{POWER CALCULATION}

The power calculation for this project is shown step by step-

\subsection{TOTAL POWER CONSUMED FROM POWER BANK}

In this project, the power consumed is -

Raspberry pi3b - Idle - 230mA (1.13W)

$400 \%$ CPU load - 730mA (3.7W)

When connected to a power meter, average $4.7 \mathrm{~W}$ power is consumed by it.

$1.7 \mathrm{~W}$ is consumed by Arduino itself in an average.

Standard Servo $-(0.8 \mathrm{~A} \times 5 \mathrm{~V}=4 \mathrm{~W})$

White line sensor $-(0.75 \mathrm{~A} \times 3.3 \mathrm{~V}=2.47 \mathrm{~W}$ approximate $)$

Buzzer $-(0.015 \mathrm{~A} \times 5 \mathrm{~V}=0.09 \mathrm{~W})$

Micro Servo $-(0.55 \mathrm{~A} \times 5 \mathrm{~V}=2.75 \mathrm{~W})$

\subsection{TOTAL POWER CONSUMED FROM BATTERY}

The two Johnson motors and the L298N motor driver are connected to DC battery. Here, the power consumed is -

Johnson motors $-2 \times(4.3 A \times 12 \mathrm{~V})=51.6 \mathrm{~W}$

$\mathrm{L} 298 \mathrm{~N}-(0.004 \mathrm{~A} \times 5 \mathrm{~V}=0.02 \mathrm{~W})$

Hence, the power bank will last long for:

Total Power $=(4.7+1.7+4+2.47+0.09+2.75) \mathrm{W}$

$=15.91 \mathrm{~W}$

$W=V \times I$

or, $15.91=5 \times I$

or, $\mathrm{I}=3.182 \mathrm{~A}$.

Therefore, the power bank will last up to

$(10.000 A h) \div 3.182 A=3.142 h$.

Yet, all the sensors and actuators do not work all the time together. Hence, from practical experience, the Power bank gives battery backup for average 20 hours.

The DC battery gives battery backup up to 5 hours.

The DYI voltmeter in Arduino to measure voltage of the battery:

It is basically a voltage divider circuit- 


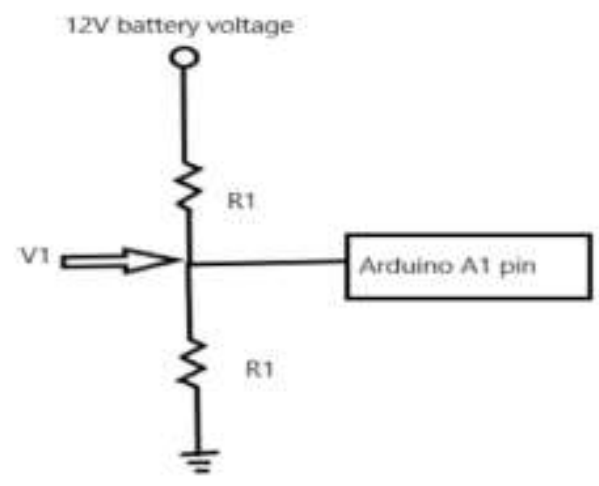

Fig. 9 Equivalent Circuit of Battery port to Ardunio

As, Arduino cannot measure greater than $5 \mathrm{~V}$ with its analog pins, a voltage divider circuit is needed.

In the above picture, $R_{1} \& R_{2}$ are two resisters in $\mathrm{k} \Omega$ range. One end of the voltage divider is to be connected to the $12 \mathrm{~V}$ battery voltage and other end to GND. Between the two resistors, the voltage measured appears in the desired range which is $5 \mathrm{~V}$ in this case.

The formula is:

$$
V_{i}=V_{m} \times R_{2} /\left(R_{1}+R_{2}\right)
$$

[In this case, $\mathrm{V}_{\mathrm{m}}=12 \mathrm{~V}$ ]

or, $5=12 \times R_{2} \div\left(47000+R_{2}\right)\left[\mathrm{R}_{1}=47000 \Omega\right.$, approx.]

$$
\text { or, } \mathrm{R}_{2}=33000 \Omega
$$

Hence, $\mathrm{R}_{2}=33 \mathrm{~K} \Omega$.

It is fact that all the components of the AntBot do not work at the same time during working period. The components are activated depending on the type of work.

When the robot has to move, its wheel and line following sensor starts to work actively. The amount of power consumption during that time:

For Arduino Nano - $1.7 \mathrm{~W}$.

For Line following sensor $-2.47 \mathrm{~W}$

For two numbers of Johnson motors $-51.6 \mathrm{~W}$

For L298N motors driver - $0.02 \mathrm{~W}$

For Raspberry PI3B $-4.7 \mathrm{~W}$

During moving period the total consumed power $60.49 \mathrm{~W}$. In fact both the arm and catcher cannot work together.

Whenever the AntBot stops moving, and lifts an weight up or down then the wheel, L298N and line following sensor will not be working actively. The amount of power consumption during that time:

For Raspberry PI3B - $4.7 \mathrm{~W}$

For Arduino Nano - $1.7 \mathrm{~W}$.

For Standard servo motor $-4 \mathrm{~W}$ 
For Micro servo motor $-2.75 \mathrm{~W}$

Total power required $13.15 \mathrm{~W}$.

\section{STRUCTURE OF THE CHARGER MODULE}

The charger module is a solar charger-based charging system. Considering the present situation of the world, the world must move forward towards renewable energy sources. It consists a solar panel, a charge controller and two leads to charge the battery coming from the load terminals of the controller. The two input terminals of charge controller are connected to the two output terminals of solar panel. The two battery terminal points of charge controller are connected to the battery.

\section{SOFTWARE PROGRAMS}

\section{Abbreviations used in this project given below:-}

Table IX. Abbreviations and their full forms

\begin{tabular}{|c|c|c|}
\hline Sr. No. & Abbreviations & Full Forms \\
\hline 1 & $\mathrm{AB}$ & Ant Bot \\
\hline 2 & $\mathrm{AH}$ & Ant Hill \\
\hline 3 & $\mathrm{BB}$ & Blue Block \\
\hline 4 & $\mathrm{CN}$ & Central Node \\
\hline 5 & GB & Green Block \\
\hline 6 & $\mathrm{~W}$ & Wood \\
\hline 7 & $\mathrm{H}$ & Honeydew \\
\hline 8 & $\mathrm{~L}$ & Leaves \\
\hline 9 & $\mathrm{~T}$ & Trash \\
\hline 10 & TDZ & Trash \\
\hline 11 & QAH & Deposition \\
\hline 3 & $\mathrm{BB}$ & Blue Block \\
\hline 4 & $\mathrm{CN}$ & Central Node \\
\hline 5 & GB & Green Block \\
\hline 6 & $\mathrm{~W}$ & Wood \\
\hline 7 & $\mathrm{H}$ & Honeydew \\
\hline 8 & $\mathrm{~L}$ & Leaves \\
\hline 9 & $\mathrm{~T}$ & Trash \\
\hline 10 & TDZ & Trash Deposition Zone \\
\hline 11 & QAH & Queen Ant Hill \\
\hline 12 & RAH & Regular Ant Hill \\
\hline 13 & $\mathrm{RB}$ & Red Block \\
\hline 14 & $\mathrm{RN}$ & Regular Node \\
\hline 15 & $S$ & Supply \\
\hline 16 & SIM & Service and Identification Marker \\
\hline 17 & TR & Trash Removal \\
\hline
\end{tabular}




\subsection{FLOWCHART}

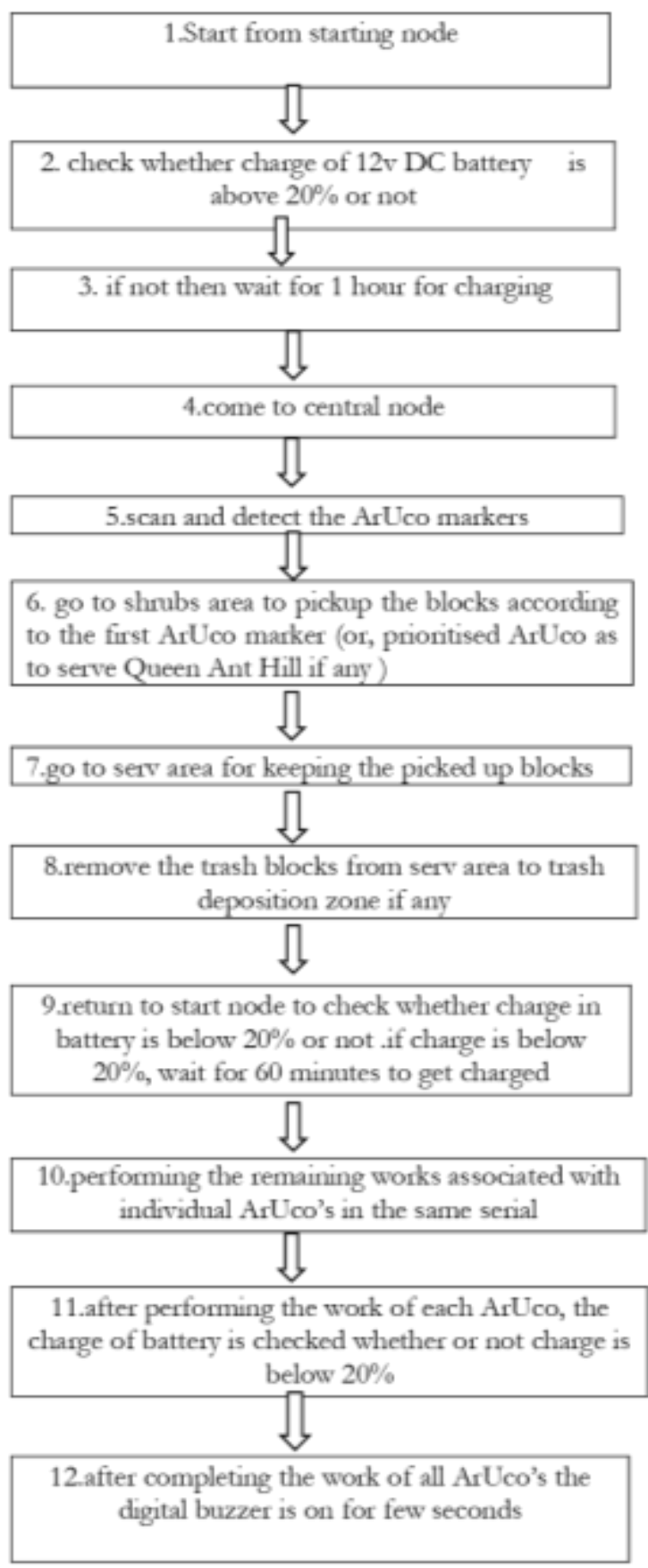

Fig. 10 Operation of AntBot by flowchart

Following the above flowchart (Fig. 10.), AntBot will complete its tasks correctly. The following pictures are the methodological output of Solar AndBot's Work. With the help of a train of programming Solar AndBot has been working in real life. Following the next pictures consistently illustrates the AndBot's way of working in real life for mankind. Not only this, the output of the program is known for its control mechanism.

\section{Press Enter}




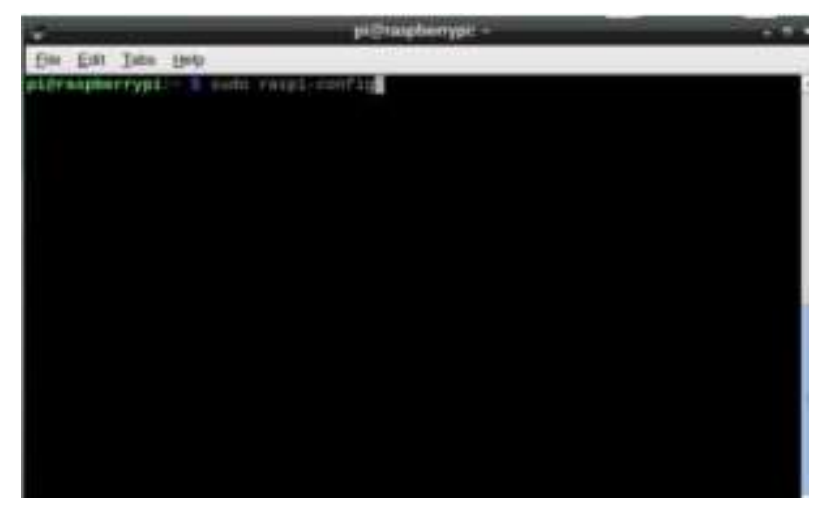

Fig. 11 Observation 1 (Configuration command)

On pressing enter, a configuration screen will appear with various configurable properties of the RPi3 as shown:

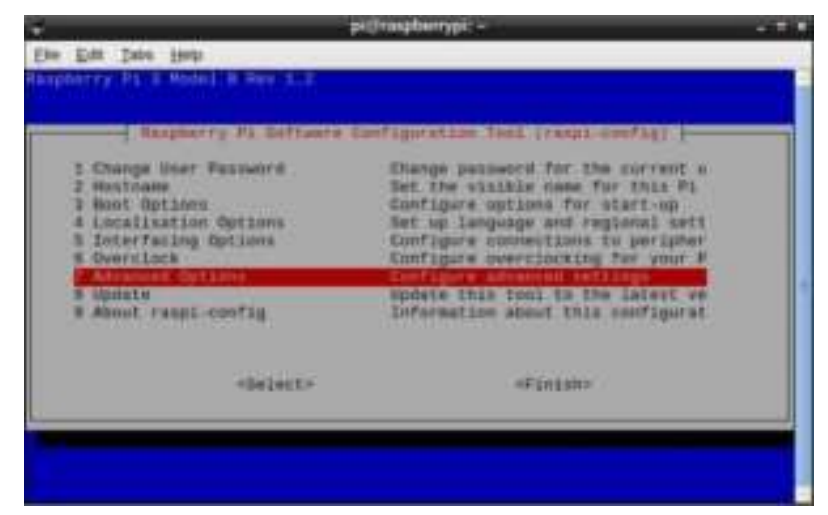

Fig. 12 Observations 2

The up-down + enter keys are to be used to select the configurable property.

The following steps are to be performed:

\section{2 .EXPAND FILE SYSTEM}

Expand File system is the main tools, available in raspi-config. The size of the Raspbian root file system is generally 2GB. To expand the root file system, firstly highlight the Expand Files stem operation and after that press Enter key. The process of extending the partition being immediately. No confirmation dialogs available here. In this case, the device can be rebooted and the expansion process lasts for a couple of minutes.

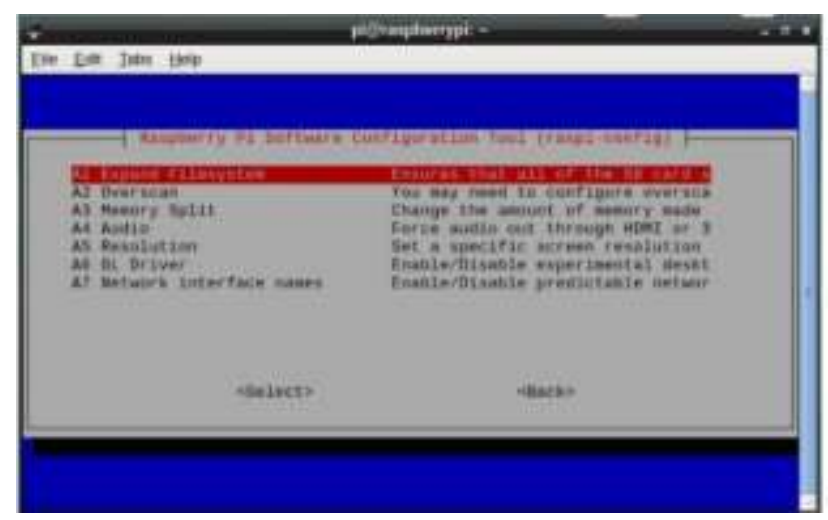

Fig. 13 Observations 3 


\section{Enter is pressed}

The following screen will appear:

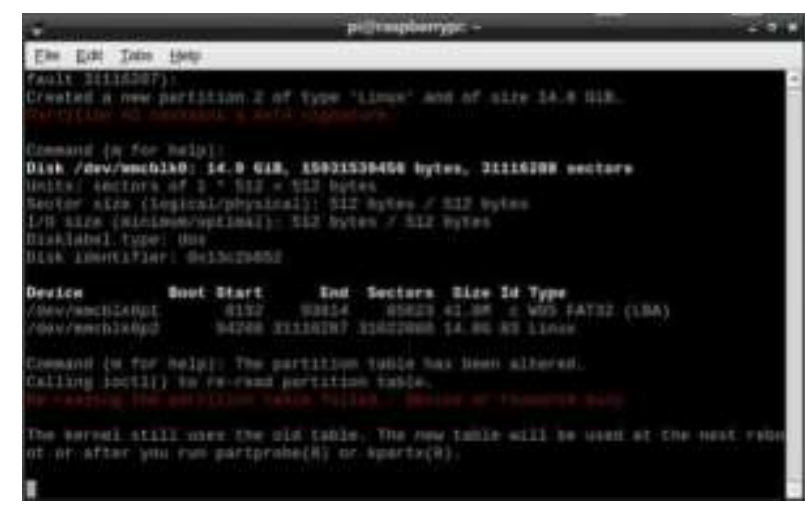

Fig. 14 Observations 4 (Expanding the file system)

This following screen will appear after that:

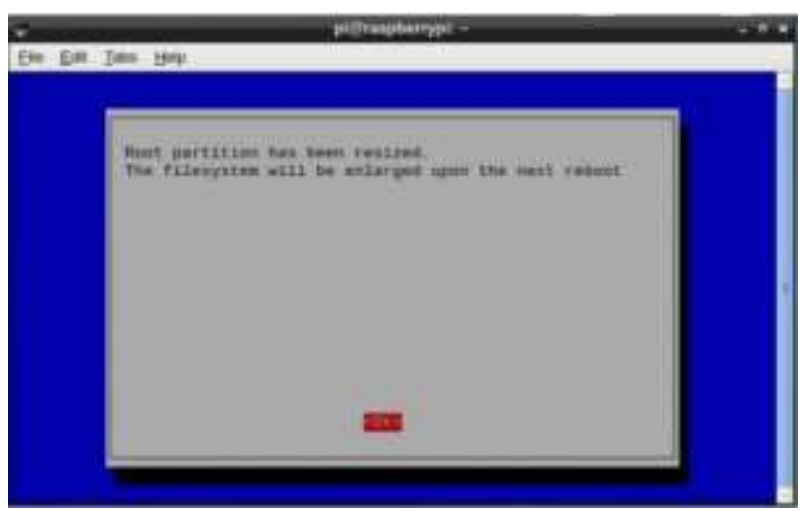

Fig. 15 Observations 5

"OK" is pressed to finish configuration.

\subsection{ENABLE PICAMERA}

In order to enable Picam, "Interfacing options" is selected.

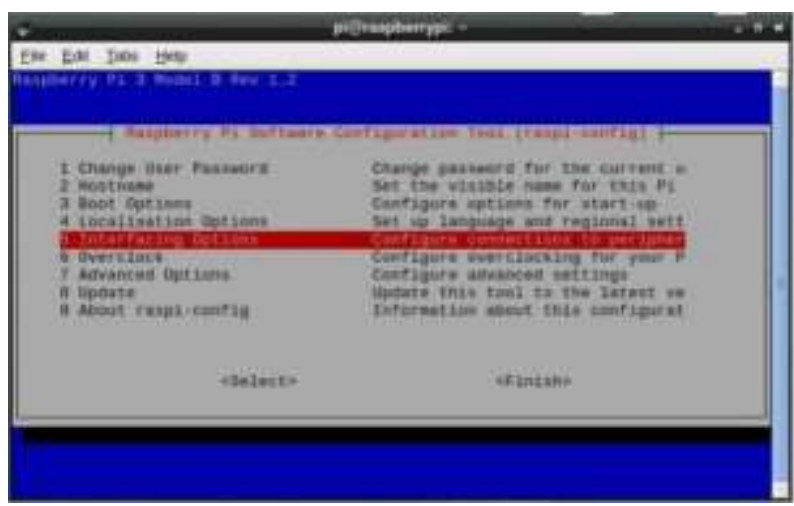

Fig. 16 Observations 6 
Then the following steps are to be followed:

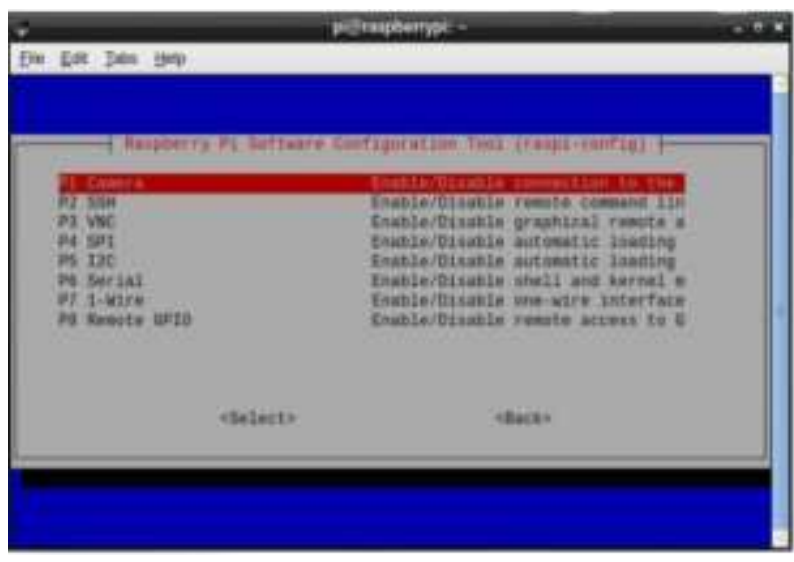

Fig. 17 Observations 7

On selecting the "Camera" option, "Yes" is pressed:

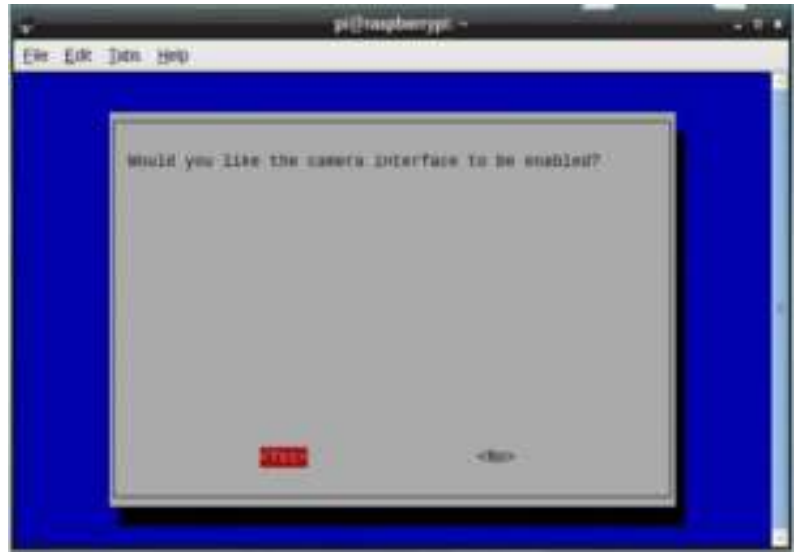

Fig. 18 Observations 8

Then "OK" is pressed

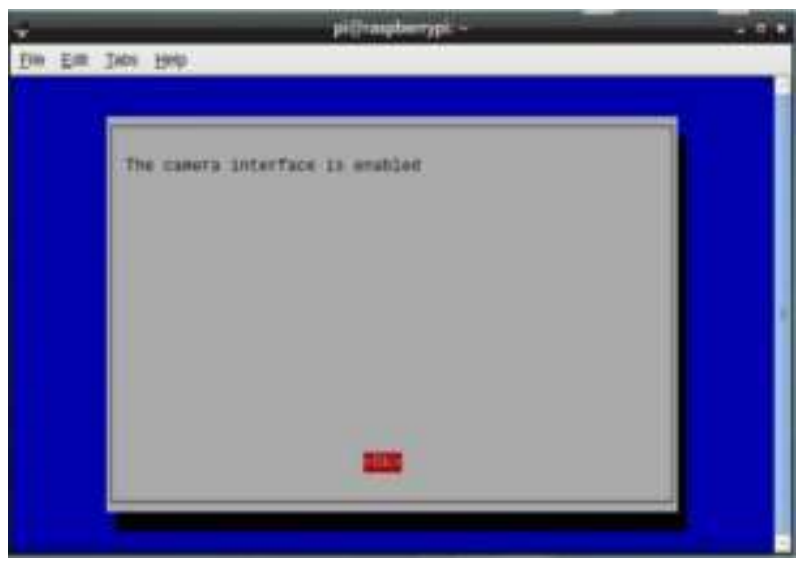

Fig. 19 Observations 9

\subsection{EXPAND MEMORY ALLOCATION}

For Picamera to work with Raspberry Pi 3B, the following steps are to be followed: 


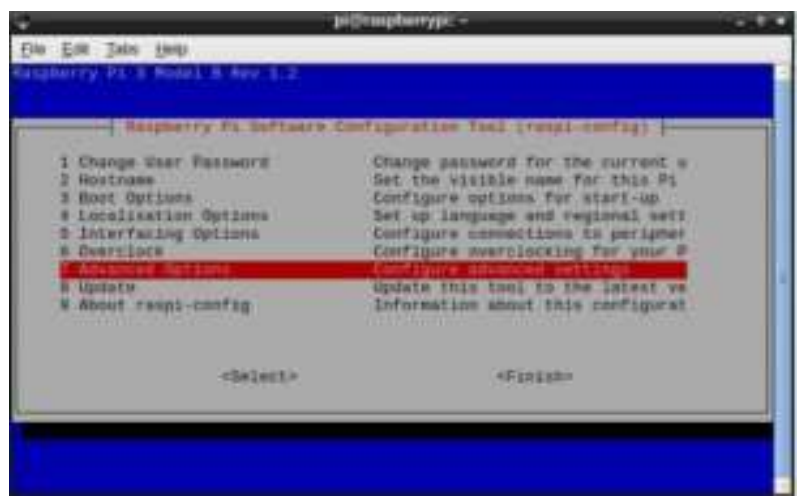

Fig. 20 Observation 10 (Advanced option is Chosen)

Then the option "Memory Split" is chosen

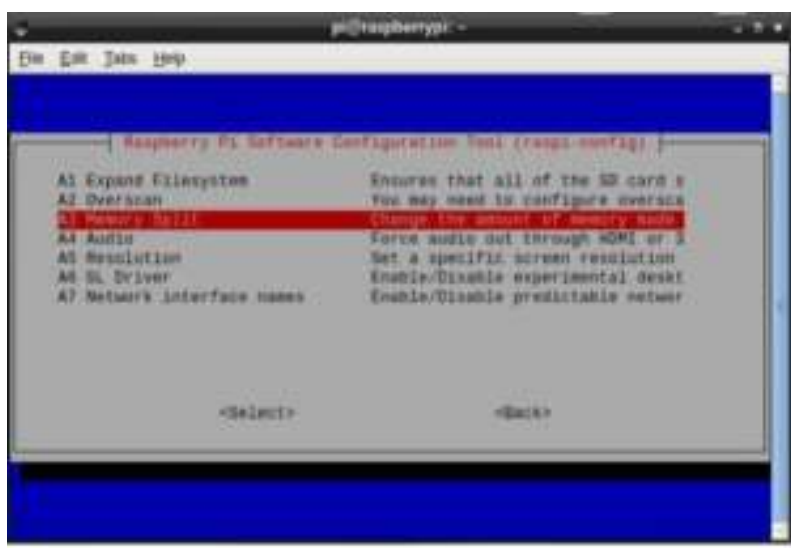

Fig. 21 Observations 11(Memory split is chosen)

Then, "256" is written in the text box given.

"OK" is pressed

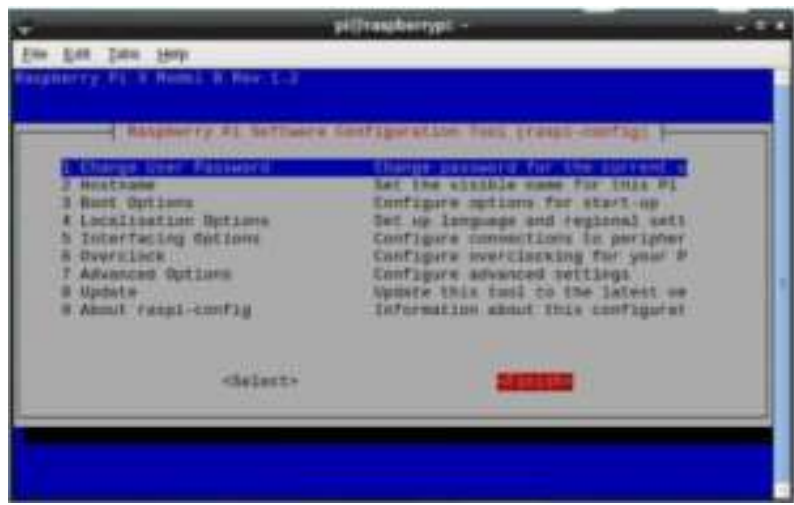

Fig. 22 Observations 12

Finally, "Finish" is pressed to finish the configuration of Raspberry Pi3B.

The tasks to be done by $\mathrm{AB}$ across the arena are same as the first ant i.e. collecting leaves, honey, wood from the Shrubs Area (SA) and store for winter and/or remove trash from its Ant Hills (AH). One of the Ant Hills, the Queen Ant's Hill (QAH) is always given preferential treatment while doing the service. 
Ant Hill (AH):Ant Hill (AH) is defined as the area where ants live. They carry required Supplies to the $\mathrm{AH}$ and remove Trash from the $\mathrm{AH}$. There are 4 such AHs depicted in the arena as Ant Hill 0 (AH0), Ant Hill 1 (AH1), Ant Hill 2 (AH2) and Ant Hill 3 (AH3). One of the AH is a Queen Ant Hill (QAH) which is a priority AH for providing Services while other are Regular AH (RAH) and are always of less priority than QAH. The information regarding which AH is5 QAH is present in Service and Identification Marker (SIM) (discussed in further points).

Note: There can be a maximum of ONLY one QAH.

Node $(\mathrm{N})$ : A Node is a small Black square of dimension $3 \mathrm{~cm} \times 3 \mathrm{~cm}$. The Node present in the centre of arena is called as the Central Node $(\mathrm{CN})$. All AHs are equidistant from the Central Node $(\mathrm{CN})$. All Nodes other than the $\mathrm{CN}$ are called as a Regular Node (RN).

Service and Identification Marker (SIM): A Service and Identification Marker (SIM) i.e. an ArUco marker is associated with each AH. Ant Bot identifies the Ant Hill number (AH0/AH1/AH2/AH3), its category (RAH or QAH) and the type of Service required by Ant Hill from the SIM. As shown in Figure 1, SIM 0 is associated with AH0, similarly, SIM 1 with AH1, SIM 2 with AH2 and SIM 3 with AH3.

Service Location (Serv):A Service location is defined as the place where AH requires Service such as placing Supply (S) or Trash Removal (TR). For a given AH there are two Service locations, Service Location 1 (Serv 1) and Service Location 2 (Serv 2).

Supply (S):An Ant Hill may have Supply Requirements as a Service requirement. These Supplies are present in the Shrubs Area (SA). There are total of 3 types of Supply as Honeydew (H), Leaves (L) and Wood (W). Supplies are denoted by blocks of Red, Green and Blue colour where, Red Block (RB) denotes Honeydew (H), Green Block (GB) denote Leaves (L) and Blue Block (BB) denotes Wood (W).

Shrubs Area (SA): This area contains supplies.

Trash Deposition Zone (TDZ):This is an area denoted by a black patch of $30 \mathrm{~cm}$ x 15 $\mathrm{cm}$ where Trash from $\mathrm{AH}$ is deposited for $\mathrm{AH}$ having Trash Removal as a Service requirement.

Trash Removal (TR): An AH may have Service requirement as Trash Removal (TR). The Trash (T) may be present in an AH at either Serv 1 or Serv 2 and is denoted by a Yellow Block (YB). Trash has to be removed from the AH and deposited in the Trash Deposition Zone (TDZ).

SIM: SIM is an ArUco marker that contains the information about the $\mathrm{AH}$ it is associated with. It is an ArUco marker belonging to dictionary DICT_7X7_1000. The ID of the marker (decimal number of the ID) contains the following data bit-wise:

i. Bit-7: If this bit is " 1 ", it denotes AH to be QAH. Otherwise, AH is RAH.

ii. Bit-6 and Bit-5: These bits denote the AH number as per the following table:

Table X. BIT-6, BIT-5 and AH NO

\begin{tabular}{|l|l|l|}
\hline BIT-6 & BIT-5 & AH NO. \\
\hline 0 & 0 & AH0 \\
\hline 0 & 1 & AH1 \\
\hline 1 & 0 & AH2 \\
\hline 1 & 1 & AH3 \\
\hline
\end{tabular}

iii. Bit-4 and Bit-3: These bits denote the Serv 2 supply requirements as:

Table XI. BIT -4, BIT-3 and Supply Frequency

\begin{tabular}{|l|l|l|}
\hline BIT-4 & BIT-3 & SUPPLY REQUIRED \\
\hline $\mathbf{0}$ & 0 & No Supply required \\
\hline $\mathbf{0}$ & 1 & Honey dew $(\mathrm{H})$ \\
\hline $\mathbf{1}$ & 0 & Leaves $(\mathrm{L})$ \\
\hline $\mathbf{1}$ & 1 & Wood $(\mathrm{W})$ \\
\hline
\end{tabular}


iv. Bit-2 and Bit-1: These bits denote the Serv 1 Supply requirements as:

Table XII. BIT -2 , BIT-1 and Supply Frequency

\begin{tabular}{|c|c|c|}
\hline BIT-2 & BIT-1 & $\begin{array}{c}\text { SUPPLY } \\
\text { REQUIRED }\end{array}$ \\
\hline 0 & 0 & No Supply required \\
\hline 0 & 1 & Honey dew $(\mathrm{H})$ \\
\hline 1 & 0 & Leaves $(\mathrm{L})$ \\
\hline 1 & 1 & Wood $(\mathrm{W})$ \\
\hline
\end{tabular}

v. Bit-0: If this bit is " 1 ", it denotes TR is required at the AH. Otherwise, TR is not required.

vi. Thus, for example, an ArUco marker with ArUco ID as 5 denotes AH0 as RAH with a TR requirement. Here, Serv 1 requirements is Leaves and thus Serv 2 requirements becomes TR. Here, ArUco ID 5 is $0 x 05$ in Hex value which in binary is $0 \times 05=00000101$ and is depicted in the bit Table below:

\begin{tabular}{|c|c|c|c|c|c|c|c|}
\hline \multicolumn{8}{|c|}{ Aruco bo tits } \\
\hline 7 & 6 & 5 & 4 & 3 & 2 & 1 & 0 \\
\hline QAH & AHEit & AHEit & $\operatorname{Sen} 2$ Eit & $\operatorname{Sen} 2$ Eit & Serv 1 bit & Sen 1 Bit & IR \\
\hline Bit & 1 & 0 & 1 & 0 & 1 & 0 & Bit \\
\hline 0 & 0 & 0 & 0 & 0 & 1 & 0 & 1 \\
\hline
\end{tabular}

Fig. 23 Observation 13

vii. Elaborating the above example further, the $\mathrm{AB}$ is supposed to pick the Green Block from the Shrubs Area. The Green Block is then to be deposited in the Ant Hill 0's Service Location 1. Also, the Yellow Block depicting Trash is to be picked from Ant Hill 0's Service Location 2 and deposited in Trash Deposition Zone.

\section{COST ANALYSIS}

1. $2200 \mathrm{mAh}$ Li-ion DC battery - 350 INR

2. $10000 \mathrm{mAh}$ power bank - $700 \mathrm{INR}$

3. RGB LED with register $10 \mathrm{INR}$

4. Micro Servo - 200 INR

5. Standard Servo - 350 INR

6. Digital Buzzer - 50 INR

7. $1 \mathrm{~K}$ potentiometer $-15 \mathrm{INR}$ each

8. Charge Controller - 600 INR

9. Solar Panel(15W, 12V) -600 INR

10. Wheeel, Catcher - 200 INR

11. Raspberry Pi -2950 INR

12. Others accessarys -550 INR

The total cost of the Solar AntBot project is 6575 INR is equal to 92.93 USD .So, in real life, the benefits are much greater than the cost of the Solar AntBot project.

\section{SOLAR ANTBOT FOR MANKIND}

With the help of modern technology, people are constantly increasing their standard of living. Technology is the main tool to reduce the work time and the running costs in people's daily life. The main advantages of Solar Antbot technology is that, firstly the running cost is very low due to the use of solar power and the technology is not so 
complicated. Secondly, the time required for the use of robotics technology is comparatively much shorter than the manual technology. This project can be directly used in real life by making some technological improvement. The cost of the project is not so high. Solar AntBot can be used for a long time, even after the solar hours because it has a power bank with its circuit. By using raspberry $\mathrm{Pi}$, the board is portable with low cost. The Raspberry Pi uses an SD card for storage, has no moving part here so noise level is almost negligible, moreover, it works as a normal computer at low cost server to handle web traffic.

\section{CONCLUSION}

The Design has been looking into the market for future scope. Solar automation will become the main technology in future research work. If implemented properly this project will lead the way in agricultural and so many others technical fields. Using this technology, there will not be any delay in work even if the power is deficient. Moreover the running cost of this project is very low because this project is related with solar energy, thereby improving the quality of life of people associated with this work. Simultaneous development of the area is possible. Proper application of this technology will bring out radical changes in the field of automated cars and restaurant catering system in future. Using the automated system has many benefits in the vehicles control area and using this technology will lead to a drastic change in the catering system in restaurant.

\section{REFERENCES}

[1] Soni, B. and Hingston P (2008). "Bots trained to play like a human are more fun," in Neural Networks, IEEE International Joint Conference on, 2008, pp. 363 -369.

[2] Bauckhage, C., Thurau C. and Sagerer G (2003) "Learning human-like op- ponent behavior for interactive computer games," in Lecture notes in Computer Science 2781, pp. 148-155..

[3] Ferna'ndez Leiva, A. and O'Valle Barraga'n J (2011) "Decision tree-based algo- rithms for implementing bot ai in ut2004," Lecture Notes in Computer Science, vol. 6686 LNCS, no. PART 1, pp. 383-392.

[4] Mart'inez, A. and Espacia A(2010) "Evolving bot ai in unrealTM ," Lecture Notes in Computer Science, vol. 6024 LNCS, no. PART 1, pp. 171- 180.

[5] Miric, S. and Nedeljkovic M (2015) “The Solar Photovoltaic Panel Simulator," Rev. Roum. Sci. Techn. Électrotechn. et Énerg., vol. 60, no. 3, pp. 273-281.

[6] Kumar, R. and Singh B (2014) "Buck boost converter fed BLDC motor drive for PV array based water pumping," IEEE International Conference on Power Electronics, Drives and Energy Systems (PEDES), pp.1-6, 16-19.

[7] Wang, H. and Zhang D (2010) "The stand-alone PV generation system with parallel battery charger," Proc. Int. Conf. Elect. Control Eng. (ICECE’10), pp. 4450-4453.

[8] Kolhe, M (2009) “Techno-economic optimum sizing of a stand-alone solar photovoltaic system," IEEE Trans. Energy Convers., vol. 24, no. 2, pp. 511-519.

[9] Debnath, D. and Chatterjee K (2015) "A two stage solar photovoltaic based standalone scheme having battery as energy storage element for rural deployment," IEEE Trans. Ind. Electron., vol. 62, no. 7, pp. 4148-4157.

[10] Krithiga, S. and Gounden N. G. A (2014) "Power electronic configuration for the operation of PV system in combined grid-connected and stand-alone modes," IET Power Electron., vol. 7, no. 3, pp. 640-647.

[11] Gallagher, M. and Ryan A (2003) "When will a genetic algorithm outperform hill climbing?" in Proceedings of the IEEE Congress on Evolutionary Computation, pp. 2462-2469.

[12] Lucas, S (2005) "Evolving a neural network location evaluator to play Ms. Pac- Man," in IEEE Symposium on Computational Intelligence and Games, pp. 203-210

[13] Szita, I. and Lo rincz A (2007) "Learning to play using low-complexity rule- based policies: illustrations through Ms. Pac-Man," Journal of Artificial Intelligence Research, vol. 30, no. 1, pp. 659684.

[14] Wirth, N. and Gallagher M (2008) “An influence map model for playing Ms. Pac-Man,” in IEEE Symposium on Computational Intelligence and Games, pp. 228-233. 
[15] Campanhol, L., Silva, S., Junior, A. and Bacon V (2017) "Dynamic performance improvement of a grid-tied PV system using a feed-forward control loop acting on the NPC inverter currents," IEEE Trans. Ind. Elec., vol. 64, no. 3, pp. 2092-2101.

[16] Radwan, A. and Mohamed Y (2016) "Power Synchronization Control for Grid-Connected CurrentSource Inverter-Based Photovoltaic Systems," IEEE Trans. Energy Conv., vol. 31, no. 3, pp. 10231036.

[17] Thawonmas, R. and Matsumoto H (2009) "Automatic controller of Ms. Pac- Man and its performance: Winner of the IEEE CEC 2009 software agent Ms. Pac-Man competition,” in Proceedings of Asia Simulation Conference.

[18] Lo'pez, E. G., Swafford, J. M., O’Neill, M. and Brabazon, A (2010) "Evolving a ms. pacman controller using grammatical evolution." in Evo Applications (1), ser. Lecture Notes in Computer Science, vol. 6024. Springer, pp. 161-170.

[19] Wittkamp, M., Barone, L. and Hingston P (2008) "Using NEAT for continuous adaptation and teamwork formation in Pacman," in Computational Intelligence and Games, 2008. CIG '08. IEEE Symposium On, dec., pp. $234-242$.

[20] Dai, J.-Y., Li, Y., Chen, J.-F. and Zhang F (2011) "Evolutionary neural network for ghost in Ms. PacMan," in Machine Learning and Cybernetics (ICMLC), 2011 International Conference on, vol. 2, pp. 732-736.

[21] P. Singh, N.M. Ravindra, Temperature dependence of solar cell performance - an analysis, Solar Energy Materials \& Solar Cells, 101, pp. 36-45 (2012)

[22] T. Labhart, Polarization-opponent interneurons in the insect visual system. Nature. 331, 435-437 (1988).

[23] H. G. Krapp, Ocelli. Curr. Biol. 19, R435-R437 (2009). 